\title{
Bone marrow transplant-induced alterations in Notch signaling promote pathologic Th17 responses to $\gamma$-herpesvirus infection
}

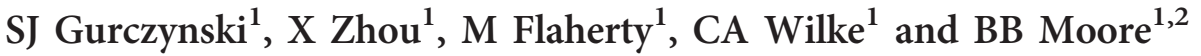

Idiopathic pneumonia syndrome (IPS) is a common, often fatal, complication following hematopoietic stem cell transplantation (HSCT) characterized by severe pneumonitis and interstitial fibrosis. Fully reconstituted syngeneic bone marrow transplant (BMT) mice infected with murine $\gamma$-herpesvirus-68 develop interleukin-17 (IL-17)-driven pneumonitis and fibrosis, which mimics clinical manifestations of IPS. We found CD103 + and CD11b + dendritic cells (DCs) are selectively deficient for the Notch ligand, DLL4, following BMT and CD4 + T cells isolated from lungs and spleens of infected BMT mice display Notch signaling defects. Mice transplanted with CD4 - Cre-driven dominant-negative Notch transcriptional regulator Mastermind-Like (CD4-Cre-DNMAML (CCD) mice) bone marrow displayed elevated IL-17 and transforming growth factor- $\beta$ (TGF $\beta$ ) in the lungs, a further expansion of T-helper type 17 (Th17) cells, and developed more fibrosis than wild-type (WT)-BMT mice. Culture of BMT lung leukocytes with recombinant Notch ligand, DLL4, restored Notch signaling and decreased production of IL-17. Adoptive transfer of CD11C + DCs could restore Th1 and limit Th17 in WT-BMT but not CCD-BMT mice, indicating that a specific DC/CD4 + T-cell Notch interaction modulates IL17 production following reconstitution in syngeneic BMT mice. Given recent clinical observations showing that patients with pulmonary complications post-transplant harbor occult herpesvirus infections, these data provide mechanistic insight and suggest potential therapies for these devastating conditions.

\section{INTRODUCTION}

Hematopoietic stem cell transplantation (HSCT) is an efficacious curative therapy for a number of malignant and autoimmune diseases. ${ }^{1,2}$ Unfortunately, severe and often fatal lung complications such as idiopathic pneumonia syndrome (IPS) and bronchiolitis obliterans syndrome are common following HSCT affecting between 10 and $15 \%$ of recipients. ${ }^{3,4}$ Aberrant production of proinflammatory cytokines such as interleukin-6 (IL-6) and IL-17A are thought to play important roles in the progression of IPS and bronchiolitis obliterans syndrome; ${ }^{5-7}$ however, the cellular mechanisms that underlie the production of these cytokines remain unclear.

The Notch pathway is an evolutionarily conserved juxtacrine intercellular signaling pathway important in a variety of biological processes such as cell division and differentiation, organ development, and lymphocyte maturation/activation. Four Notch receptors (Notch1-4) are expressed by mammalian cells and can be activated by contact with a second cell expressing one of five Notch ligands (DLL1, 3, and 4 and Jagged 1 or -2$){ }^{8,9}$ Interactions with these cognate ligands result in an initial cleavage of the Notch receptor in the plasma membrane by ADAM (A disintegrin and metalloproteinase) proteases. ${ }^{10}$ The receptor subsequently undergoes endocytosis where it undergoes a second cleavage by the intramembrane protease $\gamma$-secretase releasing an active Notch intracellular domain. The Notch intracellular domain transits to the nucleus where it acts as a scaffold for transcription machinery including p300 and master mind-like (MAML). ${ }^{11}$ The formation of this transcription complex de-represses the transcriptional repressor CBP/RBPj-K turning on the expression of Notch-specific target genes such as the Hairy enhancer of split (Hes) family of proteins. $^{12}$

Engagement of Notch receptors on CD4 $+\mathrm{T}$ cells by ligand expressing antigen-presenting cells (APCs) has been shown to

${ }^{1}$ Department of Internal Medicine, Division of Pulmonary and Critical Care Medicine, University of Michigan, Ann Arbor, Michigan, USA and ${ }^{2}$ Department of Microbiology and Immunology, University of Michigan, Ann Arbor, Michigan, USA. Correspondence: SJ Gurczynski (sgurczyn@umich.edu)

Received 13 April 2017; accepted 22 August 2017; published online 18 October 2017. doi:10.1038/mi.2017.85 
influence T-cell polarization into the various activated subsets (e.g. Th1, Th2, Th17). This process is dependent on a variety of factors including antigen and cytokine exposure and can be either activating or inhibitory. The expression of the Notch ligands DLL4 or Jagged1 by APCs was shown to preferentially result in naïve $\mathrm{T}$ cells skewing towards either Th1 or Th2, respectively. ${ }^{13}$ Exposure of naive T cells to plate-bound or APCexpressed DLL4 was shown to drive Th17 differentiation when the cells were grown in the context of the Th17-skewing cytokines, IL- 6 and transforming growth factor- $\beta$ (TGF- $\beta$ ). ${ }^{14}$ Further the IL-17 promoter was demonstrated to be a direct transcriptional target for the Notch intracellular domain complex. ${ }^{14,15}$

In contrast, several studies have shown that Notch ligand expression by APCs can attenuate T-cell cytokine expression. Expression of Jagged1 by APCs pulsed with the dust mite antigen Der P1 was found to expand populations of T-regulatory cells and induce a tolerogenic phenotype upon antigen re-exposure. ${ }^{16}$ Pulsing of bone marrow-derived dendritic cells with BCG expressing recombinant Der P2 antigen increased expression of the Notch ligand DLL4 and adoptive transfer of these bone marrow-derived dendritic cells decreased Th17 differentiation and lessened allergic airway inflammation in an experimental mouse model of asthma. ${ }^{17}$ DLL4 was also shown to be increased following respiratory syncytial virus infection. ${ }^{18}$ Treatment of respiratory syncytial virus-infected mice with $\alpha$ DLL4 antibody therapy exacerbated airway inflammation and increased IL-17 responses. ${ }^{18,19}$ More recently, $\mathrm{T}$ cells cultured with Jagged1 were found to be significantly inhibited in their ability to produce IL-17 when cocultured with the Th17-skewing cytokines IL-6 and TGF.$^{20,21}$ Additionally, $\mathrm{T}$ cells isolated from patients with systemic lupus erythematosus were found to be deficient in Notch1 signaling and produced elevated levels of IL-17A. ${ }^{22}$ Thus, the ultimate role of Notch signaling during T-cell activation is highly context dependent, highlighting the need to study this pathway in detail in specific disease states.

We have previously characterized a mouse model of pneumonitis and pulmonary fibrosis following $\gamma$-herpesvirus-68 ( $\gamma \mathrm{HV}-68)$ infection in syngeneic bone marrowtransplanted (BMT) mice that strongly resembles clinical manifestations of IPS and the fibrotic properties of bronchiolitis obliterans syndrome in humans that have undergone HSCT. In normal, nontransplanted mice, $\gamma \mathrm{HV}-68$ clearance from the lungs happens within 10 days from the onset of intranasal infection via a strong polarization of $\mathrm{CD} 4+\mathrm{T}$ cells to a Th1 phenotype secreting large amounts of interferon- $\gamma$ (IFN $\gamma$ ), which has been shown to limit the replication and spread of $\gamma \mathrm{HV}-68 .{ }^{23-25} \mathrm{BMT}$ mice, however, show an increased polarization of $\mathrm{CD} 4+\mathrm{T}$ cells to a Th17 phenotype following $\gamma \mathrm{HV}-68$ challenge, secreting IL-17 instead of IFN $\gamma$, resulting in a severe pneumonitis and pulmonary fibrosis, which is evident by 3 weeks postinfection. ${ }^{26-28}$ Neutralization of IL-17 by administration of $\alpha \mathrm{IL}-17$ antibody therapy, or genetically ablating expression of IL-17 from donor hematopoietic cells completely abrogated disease. ${ }^{27}$ It was further demonstrated that adoptive transfer of non-BMT CD11c + APCs could reverse polarization of CD4 $+\mathrm{T}$ cells back to a Th1 phenotype and alleviate the fibrosis in BMT mice infected with $\gamma \mathrm{HV}-68$, demonstrating a role for an APC-T-cell interaction in this altered immune response. ${ }^{27}$

Given the important role of Notch signaling in T-cell activation, we asked whether Notch signaling was involved in regulating cytokine production from T cells following $\gamma \mathrm{HV}-68$ challenge after BMT. T cells isolated from the lungs and spleens of BMT mice had significant decreases in the expression of Notch-associated transcription factors following $\gamma \mathrm{HV}-68$ infection. Further, BMT mice transplanted with marrow specifically ablated for canonical Notch signaling only in CD4 and CD8 T cells exhibited increased the number of lunginfiltrating Th17 cells, higher levels of pathogenic IL-17 and TGF- $\beta$ production, and developed more exuberant pulmonary fibrosis, indicating that $\mathrm{T}$-cell Notch signaling is an important regulator of profibrotic cytokines following BMT and $\gamma \mathrm{HV}$ infection.

\section{RESULTS}

\section{Lung DCs display reduced expression of DLL4 in virally infected BMT mice}

Notch ligand expression on $\mathrm{CD} 11 \mathrm{c}+\mathrm{APCs}$ has been implicated in modulating T-cell activation and cytokine production during a variety of disease states and immunological maladies. ${ }^{31-35}$ To determine whether levels of Notch ligands were altered on APCs following BMT and viral infection, total CD11c + cells were isolated by magnetic bead separation from either control or BMT mouse groups and infected ex vivo at a multiplicity of infection of 1.0 for $24 \mathrm{~h}$ with $\gamma \mathrm{HV}-68$. Total RNA was isolated and expression levels of four Notch ligands (DLL1, DLL4, Jagged1, and Jagged2) were analyzed via quantitative real-time PCR (qRT-PCR). Expression of DLL4 was decreased in both uninfected BMT cells and in infected non-BMT cells in comparison with control non-BMT $\mathrm{CD} 11 \mathrm{c}+\mathrm{APCs}$, and an additive downregulation of DLL4 was noted in infected BMT APCs in comparison with control cells ( $\sim 5$-fold downregulation in comparison with control nonBMT cells; Figure 1a). DLL1 was modestly, although not significantly, downregulated in uninfected BMT cells in comparison with wild-type (WT) control cells; however, no change was observed in cells isolated from infected mice (Figure 1a). Levels of Jagged 2 were downregulated in infected BMT CD11c + cells in comparison with WT control cells; however, no change in Jagged2 expression was noted in comparison with WT control cells (Figure 1a). No change in Jagged1 expression was observed in any of the groups (Figure 1a). To analyze expression of Notch ligands on $\mathrm{CD} 11 \mathrm{c}+$ cells in vivo, we infected groups of control or BMT mice intranasally with $\gamma \mathrm{HV}-68$. After 7 days postinfection (dpi), flow cytometry was performed on collagenase-digested lung cells to assess APC expression of Notch ligands in vivo. Cells were first gated as CD45+, CD11c +, and MHCII + before gating on expression of either DLL1, DLL4, Jagged1, or Jagged2. In agreement with the ex vivo data, significantly fewer 
a

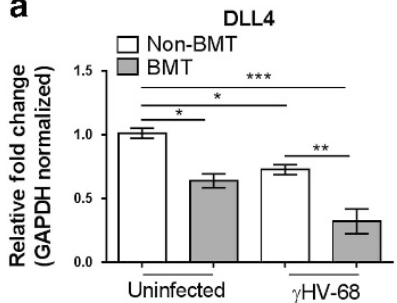

b

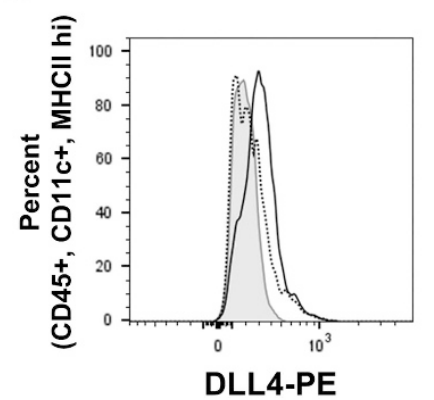

FMO control

$\square$ Non-BMT : BMT
DLL1

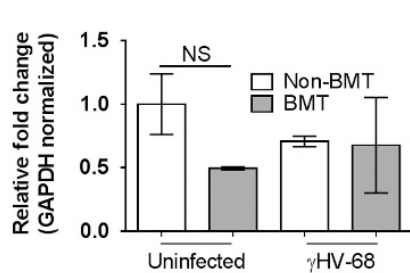

c

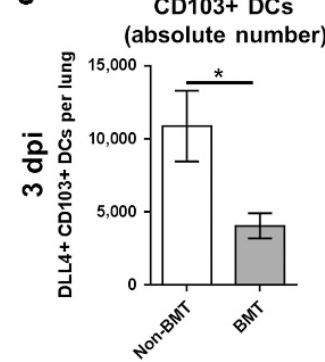

d

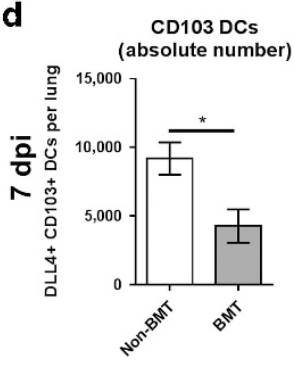

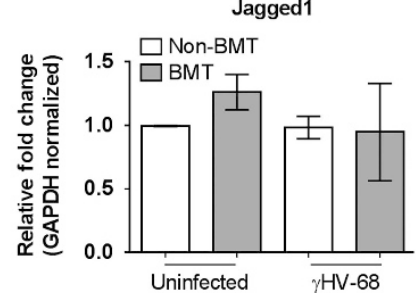

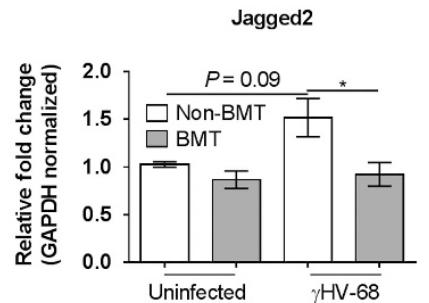

CD103+ DCs (percentage)
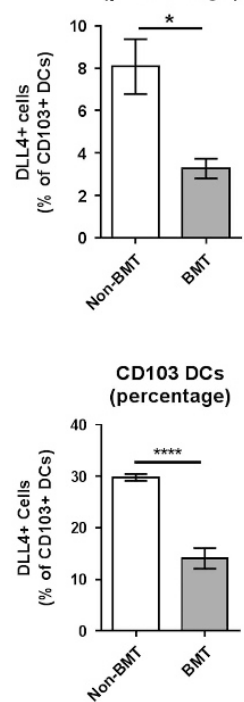

CD11b+ DCs

(absolute number)
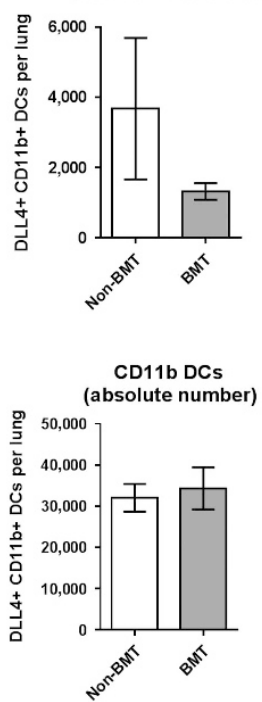

CD11b+ DCs

(percentage)
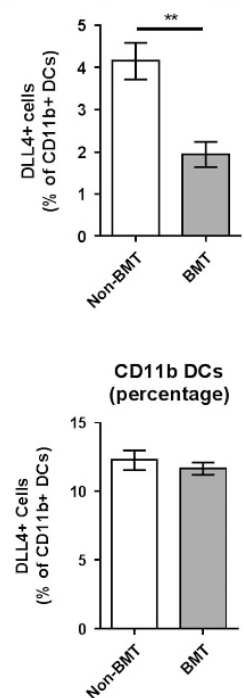

e

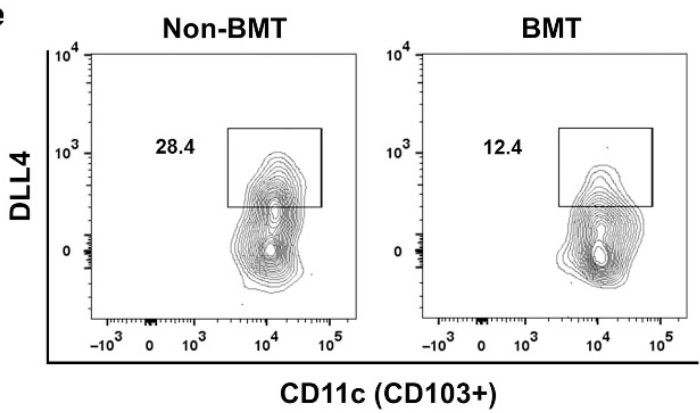

f

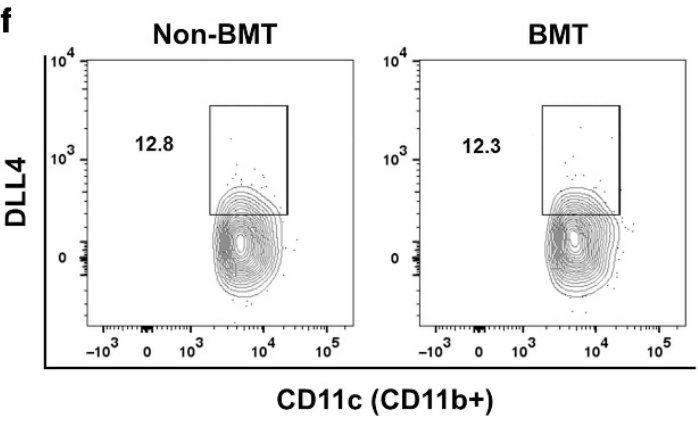

Figure 1 Loss of Notch ligand expression in lung-associated antigen-presenting cells (APCs) following bone marrow transplant (BMT). (a) Total lung $\mathrm{CD} 11 \mathrm{c}+$ cells were magnetically isolated ( $n=4$ mice per group) and infected ex vivo with $\gamma$-herpesvirus-68 (HV-68). After 24hours postinfection (hpi), the indicated transcript expression level was analyzed via quantitative real-time PCR (qRT-PCR). (b) Flow cytometric analysis of DLL4-expressing APCs. Cells were first gated on $\mathrm{CD} 45+, \mathrm{CD} 11 \mathrm{C}+$, and MHCII + before gating on DLL4. Expression is compared with a flow minus one (FMO) control. (c and d) DLL4 expression in CD11c + subsets were assessed by flow cytometry. Cells were first gated on CD45 +, CD11C +, MHCII +, and CD64 - and then subdivided as either CD103 + or CD11b + . Graphed are absolute number or percentage of both CD103 + or CD11b + dendritic cells (DCs). Mean values are graphed ( \pm s.e.m.), statistical significance was calculated using analysis of variance (ANOVA) (panel a) or Student's T-test (panel c), ${ }^{\star} P<0.05,{ }^{\star *} P<0.01$, and ${ }^{* \star *} P<0.001$; NS $=$ not significant. (e and $\mathbf{f}$ ) Representative flow plots showing percentages of DLL4 + cells from either CD103 + or CD11b + DCs.

DLL4-positive CD11c + cells were detected in the lungs of BMT mice at $7 \mathrm{dpi}$ in comparison with non-BMT mice (Figure $\mathbf{1 b}$ and Supplementary Figure S1 online). The number of CD11c + APCs expressing DLL1, Jagged1, or Jagged2 was not altered in $\gamma \mathrm{HV}-68$-infected BMT mice in vivo (Supplementary Figure S1).

We further analyzed the expression of DLL4 on two distinct subsets of CD11c + DCs, i.e., CD103 + and CD11b + DCs, by flow cytometry. In agreement with the decreased expression of
DLL4 seen in the total CD11c + DC compartment, the absolute number as well as the percentage of DLL4 + CD103 + DCs present in the lungs of BMT mice was significantly decreased at 3 dpi (Figure 1c). Percentage of CD11b + DCs was similarly decreased in BMT mice at $3 \mathrm{dpi}$; however, there was not a statistically significant decrease in the absolute number (Figure 1c). Similarly, at 7 dpi both absolute number and percentage of CD103 + DCs was decreased in BMT mice, and no change in either absolute number or percentage of $\mathrm{CD} 11 \mathrm{~b}+$ 
DCs was observed at 7 dpi (Figure 1d). Representative flow plots (7 dpi) are shown for CD103 + DCs in Figure 1e, and for CD11b + DCs in Figure 1f, the full flow cytometry gating strategy is shown in Supplementary Figure S2.

We next isolated CD4 $+\mathrm{T}$ cells from the spleen as a source of naïve T cells from uninfected WT or BMT mice (0 dpi) or from the lungs of $\gamma \mathrm{HV}$-68-infected mice $(7 \mathrm{dpi})$ and analyzed expression of the Notch target genes Hes1, Hes5, and Hey1, as well as the Notch1 and Notch2 receptors by qRT-PCR. Interestingly, in the absence of infection, expression of both Notch1 and Notch2, as well as all three Notch target genes, were decreased in $\mathrm{T}$ cells isolated from the spleens of BMT mice (Figure 2). At $7 \mathrm{dpi}$, the expression of Notch1 and Hes1 were significantly lower in $\mathrm{T}$ cells isolated from the lungs; however, the expression of Hes5 and Heyl were not significantly different between BMT and WT mice and an increase in the expression of Notch 2 was also noted (Figure 2).

\section{Abrogation of T-cell Notch signaling enhances Th17 differentiation and exacerbates $\gamma \mathrm{HV}$-68-induced pulmonary fibrosis following BMT}

To assess whether T-cell-specific Notch signaling influenced Th17 differentiation during $\gamma \mathrm{HV}-68$ infection following syngeneic BMT, we used a genetic approach wherein C57BL/6J mice harboring a Cre recombinase under the control of the $\mathrm{CD} 4$ promoter were crossed with mice carrying a floxed dominant-negative version of the Notch transcriptional regulator MAML. ${ }^{29}$ These CCD mice retain a normal repertoire of $\mathrm{T}$ cells but are functionally ablated for all canonical Notch signaling in both CD4 + and CD8 + T cells. Syngeneic BMTs were performed on lethally irradiated WT mice using either WT or CCD mice as donors. Following this, both transplanted and nontransplanted control groups were infected intranasally with $\gamma \mathrm{HV}-68$. Lungs were harvested at $7 \mathrm{dpi}$, collagenase digested, and analyzed by intracellular cytokine staining and flow cytometry for expression of either IFN $\gamma$ or
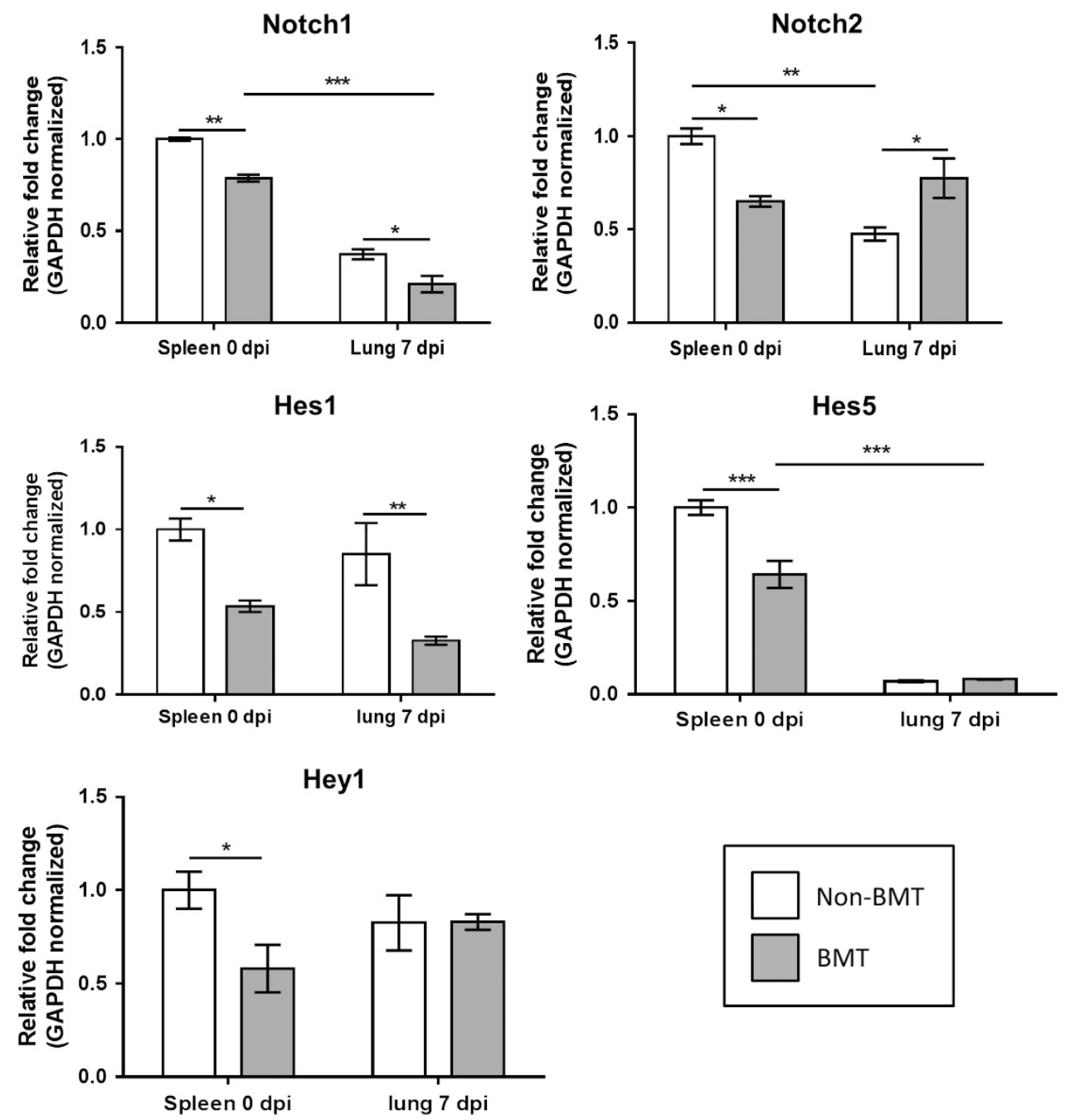

Figure 2 CD4 + T cells isolated from bone marrow transplant (BMT) mice are deficient in Notch signaling. RNA was isolated from CD4 + T cells purified from either the spleens of naïve non-BMT or BMT mice ( 0 days postinfection (dpi)) or the lungs at 7 dpi $(n=3-4$ mice per group) and analyzed via quantitative real-time PCR (qRT-PCR) for the expression of the indicated transcript. Statistical significance was calculated by analysis of variance (ANOVA). ${ }^{\star} P<0.05,{ }^{\star \star} P<0.01$, and ${ }^{* \star \star} P<0.001$. 
IL-17 to assess Th1 and Th17 populations, respectively. Following $\gamma \mathrm{HV}$-68 challenge, CCD mice lacking T-cell Notch signaling had a significantly greater number of IL-17-producing $\mathrm{CD} 4+$ cells in the lungs in comparison with nontransplanted control or WT BMT mice (Figure 3a,b). Additionally, CCD mice had significantly fewer IFN- $\gamma$ producing $\mathrm{CD} 4+\mathrm{T}$ cells than nontransplanted control mice (Figure 3a,c). Because the DNMAML transgene is a
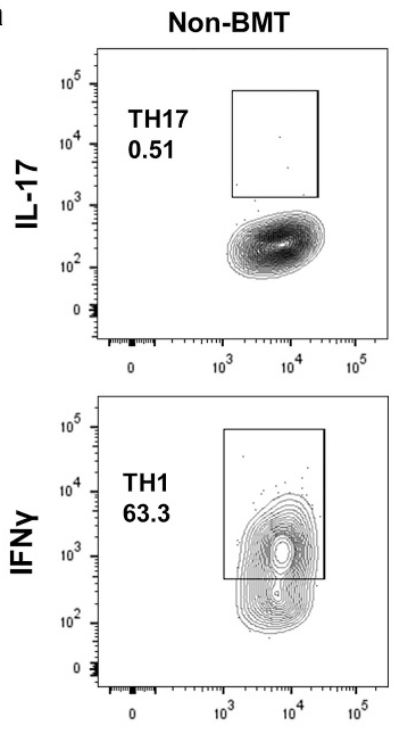
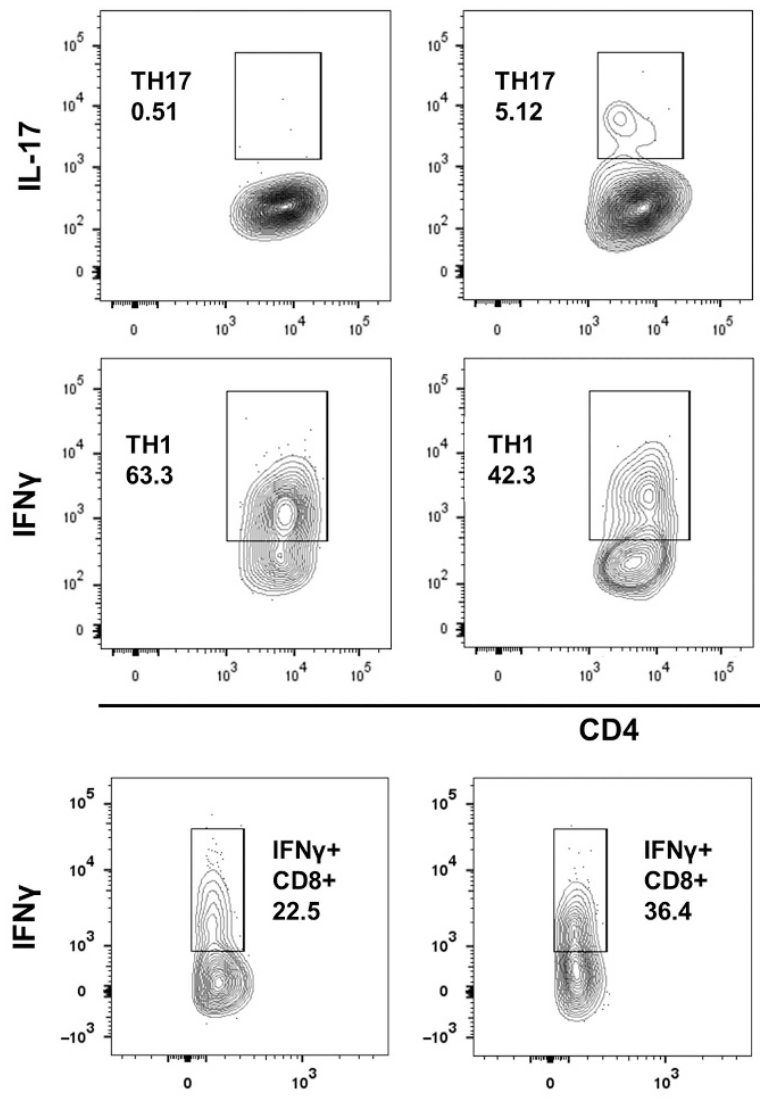

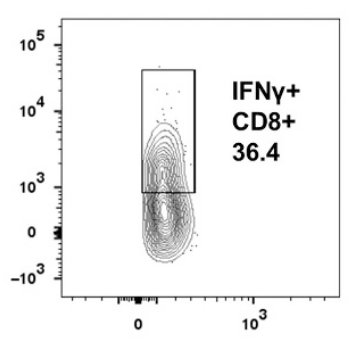

\section{CD8}

BMT

CD4

CCD-BMT
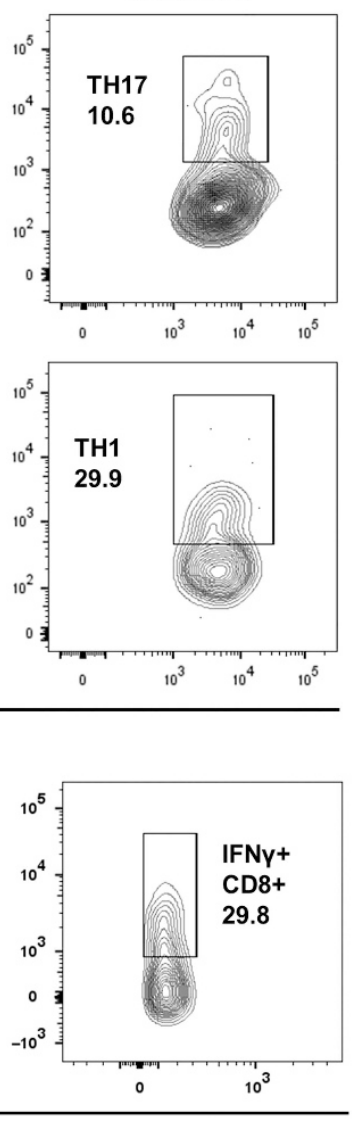

$\mathbf{f}$ b
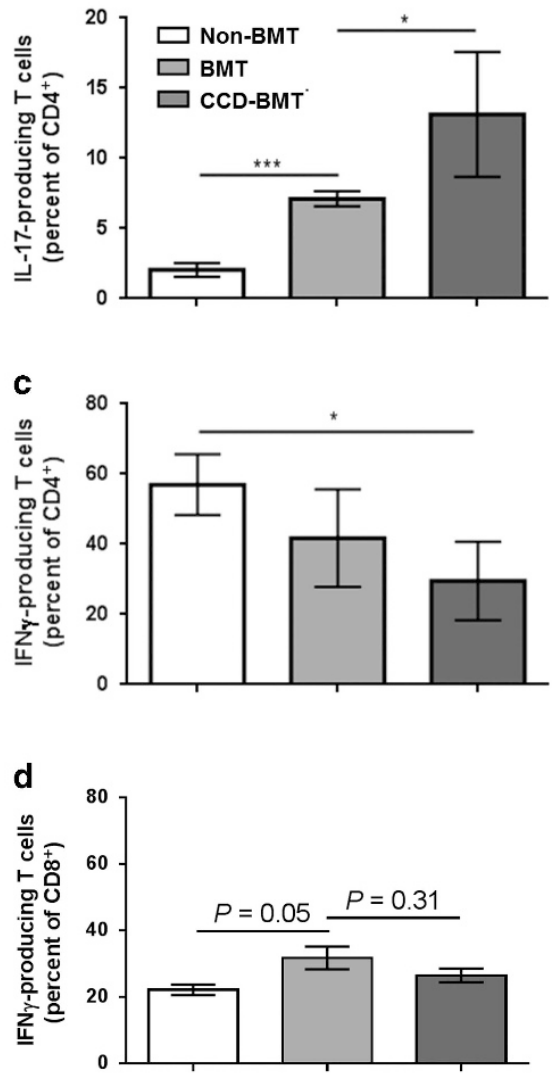
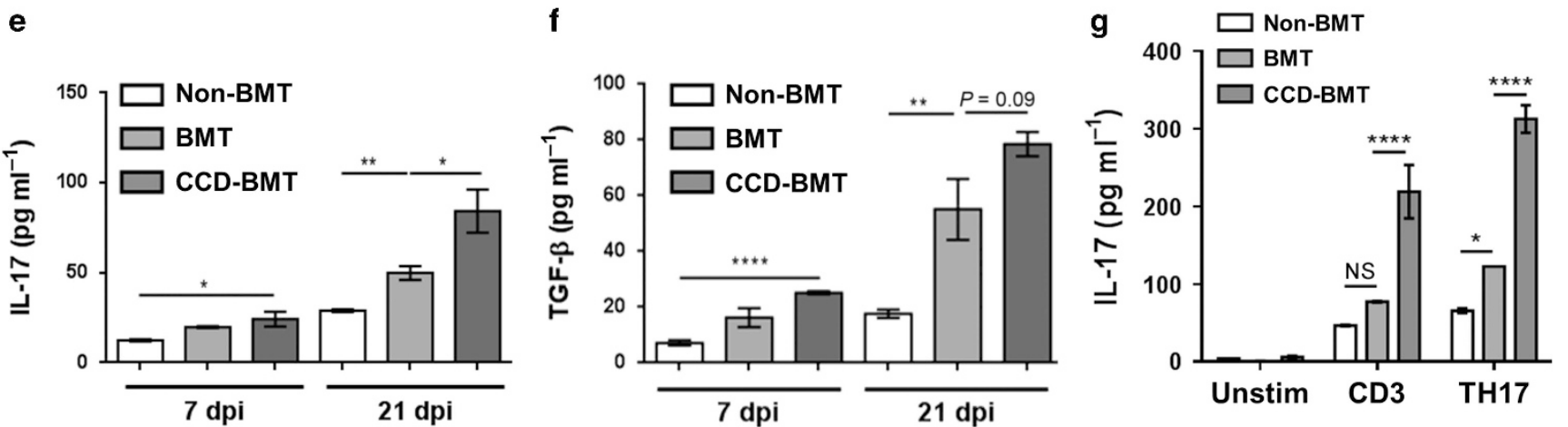

Figure 3 Loss of T-cell Notch signaling increases production of interleukin-17 (IL-17) from CD4 + lymphocytes following bone marrow transplant (BMT). Control or BMT mice ( $n=4-5$ mice per group) were infected with $\gamma$-herpesvirus-68 ( $\gamma \mathrm{HV}-68)$ for 7 days. Lungs were harvested and collagenase digested. Following phorbol 12-myristate 13-acetate (PMA) and ionomycin stimulation, cells were analyzed by flow cytometry for either IL-17 or interferon- $\gamma$ (IFN $\gamma$ ) producing CD4 + or CD8 + T cells. (a) Representative flow-plots showing percentages of T-helper type 17 (Th17), Th1, or IFN $\gamma+$ CD8 + cells present in the lungs of control, BMT or CD4-Cre-DNMAML-BMT (CCD-BMT) mice at 7 days postinfection (dpi). (b-d) Quantification of data represented in (a). (e and f) Leukocytes from collagenase-digested lungs were purified by centrifugation through Percoll. Cells were cultured overnight in complete media, without additional stimulation, and clarified supernatants were analyzed by enzyme-linked immunosorbent assay (ELISA). (g) CD4 + T cells were magnetically purified from the spleens of either wild-type (WT), BMT, or CCD-BMT mice ( $n=3-4$ mice per group), $1 \times 10^{6}$ cells were cultured in the presence of the indicated skewing condition for $24 \mathrm{~h}$, after which supernatants were harvested and analyzed for the indicated cytokine by ELISA (Unstim $=$ no additives, CD3 $=1 \mu \mathrm{g} \mathrm{ml}^{-1} \alpha \mathrm{CD} 3$ and $\alpha \mathrm{CD} 28$, Th17 $=\alpha \mathrm{CD} 3, \alpha \mathrm{CD} 28$, with $2 \mathrm{ng} \mathrm{ml}^{-1}$ transforming growth factor- $\beta$ and $20 \mathrm{ng} \mathrm{ml}{ }^{-1} \mathrm{IL}-6$ ). Statistical significance was calculated by analysis of variance (ANOVA). ${ }^{\star} P<0.05,{ }^{* \star} P<0.01,{ }^{\star * \star} P<0.001$, and ${ }^{* \star * \star} P<0.0001$. 
expressed by both $\mathrm{CD} 4+$ and $\mathrm{CD} 8+\mathrm{T}$ cells during the double-positive stage of lymphocyte maturation, we also analyzed CD8 + lymphocyte populations for the expression of both IL-17 and IFN $\gamma$. In contrast to CD $4+\mathrm{T}$ cells, there was no difference in $\mathrm{CD} 8+$ IFN $\gamma$ expression between $\gamma \mathrm{HV}-68$ infected WT-BMT and CCD-BMT mouse groups (Figure 3a,d). Additionally, IL-17 was only detected in a small population of $\mathrm{CD} 8+\mathrm{T}$ cells in BMT mice $(<1 \%)$ and there was no difference between $\gamma \mathrm{HV}$-68-infected BMT and CCD-BMT mice (data not shown).

To further assess the levels of cytokines produced by control and BMT mice after $\gamma \mathrm{HV}-68$ challenge, cells from collagenasedigested lungs were purified by centrifugation through Percoll at 7 or $21 \mathrm{dpi}$, resulting in a $60-80 \%$ enrichment for CD $45+$ hematopoietic cells as assayed by flow cytometry (Supplementary Figure S2, panel 1). Cells were plated for $24 \mathrm{~h}$ in complete media ( $3 \times 10^{6}$ per sample) and the amount of profibrotic cytokines IL-17 and TGF- $\beta$ was measured by enzyme-linked immunosorbent assay (ELISA). In agreement with the greater number of Th17 cells recruited to the lungs of CCD-transplanted mice, cells isolated from the lungs of CCDBMT mice produced more IL-17 and TGF- $\beta$ than nontransplanted control or WT BMT mice at both 7 and 21 dpi (Figure 3e,f). Additionally, CD4 $+\mathrm{T}$ cells were isolated from the spleens of noninfected control, WT-BMT, or CCDBMT mice and stimulated either with $\alpha \mathrm{CD} 3 / \alpha \mathrm{CD} 28$ alone or with $\alpha \mathrm{CD} 3 / \alpha \mathrm{CD} 28$ in conjunction with the Th17-skewing cytokines IL- 6 and TGF- $\beta$. CD $4+$ T cells isolated from CCDBMT mice produced large quantities of IL-17 even in the absence of Th17-skewing cytokines and IL-17 production was further amplified in the presence of IL- 6 and TGF- $\beta$ (Figure 3g).

\section{Loss of T-cell Notch signaling exacerbates $\gamma \mathrm{HV}$-68-induced pulmonary fibrosis following BMT}

To address whether the increased levels of IL-17 produced by CCD mice in response to $\gamma \mathrm{HV}-68$ exacerbated the development of pulmonary fibrosis, hematoxylin and eosin, and Trichrome staining of formalin-fixed paraffin-embedded lung sections were examined microscopically for the presence of inflammation and fibrotic foci at 21 dpi. Masson's Trichrome staining highlights collagen-rich fibrotic areas with a blue color. Nontransplanted control mice infected with $\gamma \mathrm{HV}-68$ had no indication of inflammation or pulmonary fibrosis at $21 \mathrm{dpi}$ (Figure 4a,b), while infected BMT mice developed patchy fibrosis as evidenced by areas of interstitial thickening, inflammatory infiltrate, loss of alveolar structure, and deposition of excess collagen (Figure $4 \mathbf{c}, \mathbf{d}$ ). CCD-BMT mice, however, developed a much more severe pneumonitis and fibrosis in response to $\gamma \mathrm{HV}-68$ with large areas of the lung showing loss of alveolar architecture, increased amounts of inflammatory infiltrate, and further increased collagen deposition (Figure 4e,f). Interestingly, non-BMT CCD mice infected with $\gamma \mathrm{HV}-68$ for 21 days did not develop pulmonary fibrosis (Supplementary Figure S3A,B). Cytokine analysis from non-BMT WT or CCD mice revealed that although non-
BMT CCD mice produced less IFN $\gamma$ at 7 dpi, levels of IL-17 were equivalent between the two groups (Supplementary Figure S3D,E). Lung collagen content was directly quantified from either WT, BMT, or CCD-BMT mice at 21 dpi by hydroxyproline assay. In agreement with the increase in collagen noted by Masson's Trichrome staining, CCD-BMT mice had more collagen deposition than either WT or WTBMT mice at 21 dpi (Figure $\mathbf{4 g}$ ). We further assayed lungs for amounts of infectious virus present at $7 \mathrm{dpi}$ and noted a significant increase in viral load in the lungs of CCD-BMT mice in comparison with either WT or WT-BMT mice (Figure 4h). To assess if CCD-BMT mice had a defect in viral clearance, we isolated total RNA from collagenase-digested lung cells at either 7 or $21 \mathrm{dpi}$ and performed qRT-PCR for two viral transcripts ( $v D N A$ polymerase and glycoprotein $B)$. Levels of both transcripts followed similar trends with transplanted mouse groups exhibiting increased expression at $7 \mathrm{dpi}$ in comparison with non-BMT mice (Figure 4i,j). At $21 \mathrm{dpi}$, expression of both viral transcripts was significantly lower in all groups, indicating that viral clearance was preserved in both BMT and CCD-BMT mice (Figure 4i,j).

\section{Adoptive transfer of WT CD11c + cells into CCD-BMT mice fails to restore T-cell Notch signaling and does not rescue fibrotic lung pathology}

We previously reported that adoptive transfer of WT CD11c + cells into BMT mice could rescue fibrotic pathology by decreasing production of IL-17 from CD4 $+\mathrm{T}$ cells. ${ }^{27}$ To address the role of APC/T-cell Notch signaling in this system, we adoptively transferred magnetically sorted CD11c + cells isolated from the lungs of $\gamma \mathrm{HV}$-68-infected WT mice into either WT-BMT or CCD-BMT mouse groups one day before infection with $\gamma \mathrm{HV}-68\left(1 \times 10^{6} \mathrm{CD} 11 \mathrm{c}+\right.$ cells transferred intravenously). As reported previously, adoptive transfer of CD11c + APCs completely rescued fibrotic pathology in WTBMT mice (Figure 5a,b). Interestingly, collagen-rich fibrotic nodes were still evident in the lungs of adoptively transferred T-cell Notch-deficient CCD-BMT mice at 21 dpi (Figure 5c,d). We next assessed if the adoptive transfer of CD11c + cells could restore the number of DLL4 + cells to either the lungs or draining lymph nodes of BMT mice following $\gamma \mathrm{HV}-68$ infection. Interestingly, the number of DLL4 + CD103 + DCs were increased in the lungs by $7 \mathrm{dpi}$ following adoptive transfer (Figure 5e). In contrast, the number of CD11b + DCs remain unchanged in the lungs and the number of both DLL4 + CD103 + and CD11b + DCs remained low in the draining lymph nodes of both BMT and adoptively transferred BMT mice. To address directly the effects of CD11c + cell transfer on T-cell Notch signaling, CD4 + T cells were isolated from the lungs of either WT, BMT, or CCD-BMT mice at 7 dpi with or without CD11c + APC adoptive transfer. Nontransferred WT-BMT CD4+ cells expressed significantly lower amounts of the Notch target Hes1 in comparison with WT CD4+ cells (Figure 5f). Adoptive transfer of $\mathrm{CD} 11 \mathrm{c}+$ cells significantly increased Hes 1 

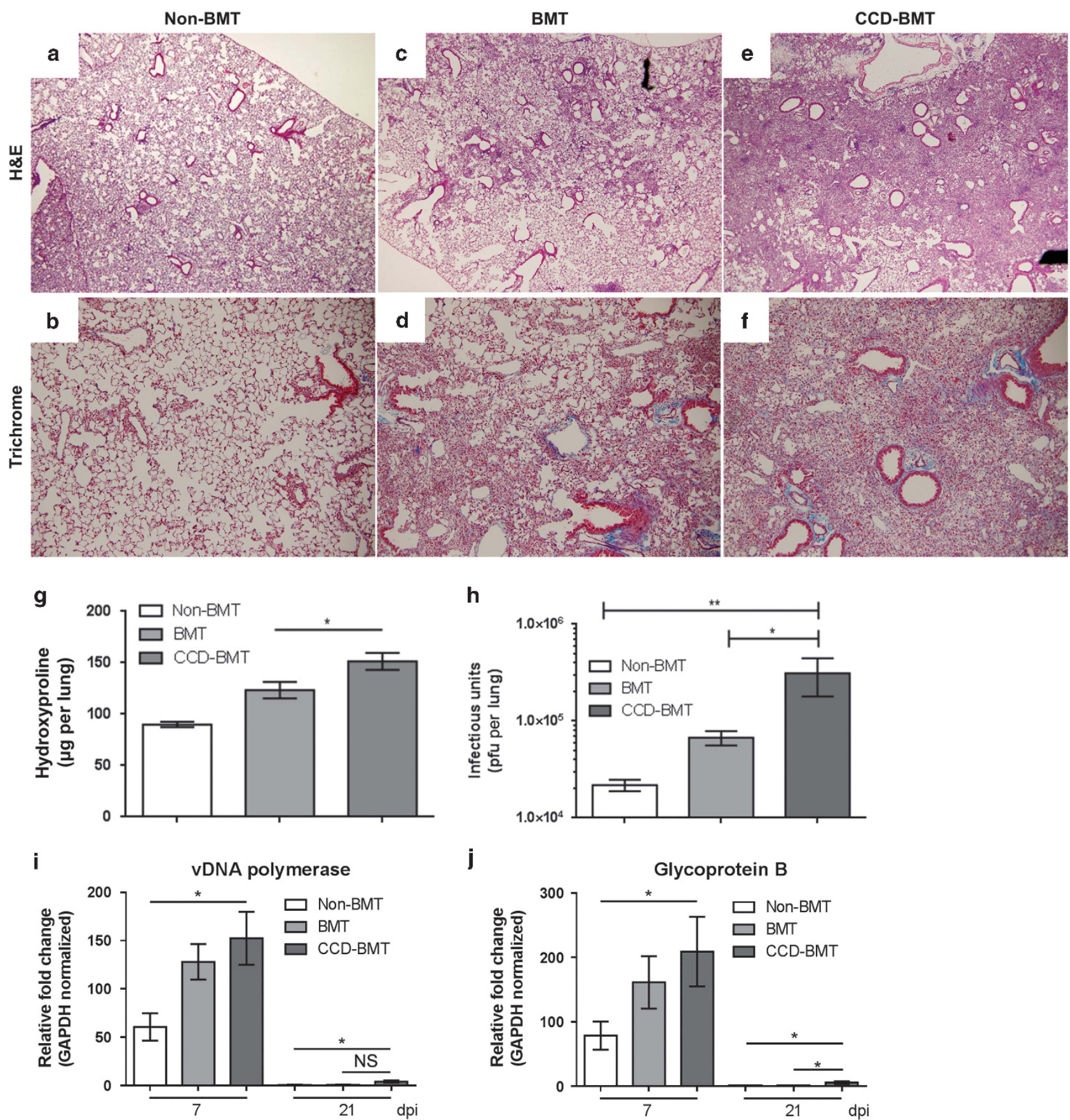

Figure 4 Disruption of T-cell Notch signaling exacerbates $\gamma$-herpesvirus-68 ( $\gamma \mathrm{HV}$-68)-induced pulmonary fibrosis following bone marrow transplant (BMT), but does not alter viral clearance. (a-f) Control or BMT mice were infected for 21 days with $\gamma \mathrm{HV}-68$. Formalin-fixed paraffin-embedded (FFPE) sections were stained with hematoxylin and eosin (H\&E) (a: untransplanted control; c: WT-BMT; e: CD4-Cre-DNMAML-BMT (CCD-BMT), original magnification $\times 40$ ) or Masson's trichrome (b: WT; $\mathbf{d}$ : WT-BMT; f: CCD-BMT, original magnification $\times 100)$. (g) Quantification of total lung collagen as measured by hydroxyproline assay at 21 days postinfection (dpi) ( $n=7-12$ mice per group). (h) Quantification of lung-associated infectious virus as measured by plaque assay ( $n=4-5$ mice per group).) (i and $\mathbf{j})$ Total RNA was isolated from collagenase-digested lung cells and analyzed via quantitative real-time PCR (qRT-PCR) for the indicated viral transcript ( $n=4-5$ mice per group). Mean values are graphed ( \pm s.e.m.), and statistical significance was calculated using analysis of variance (ANOVA). ${ }^{\star} P<0.05$ and ${ }^{* *} P<0.01$.

expression in WT-BMT CD4+ cells, but failed to increase Hes1 expression in CCD-BMT CD4 + cells (Figure 5f). Lower numbers of Th17 cells were detected by flow cytometry in the lungs of WT-BMT mice that had received CD11c + cellular adoptive transfer; however, CCD-BMT mice still had significantly elevated numbers of lung-infiltrating Th17 cells after transfer of CD11c+ cells (Figure 5g). To address whether the adoptive transfer of CD11c + cells had an ameliorative effect on the development of pulmonary fibrosis, we analyzed lung collagen content at 21 dpi by 

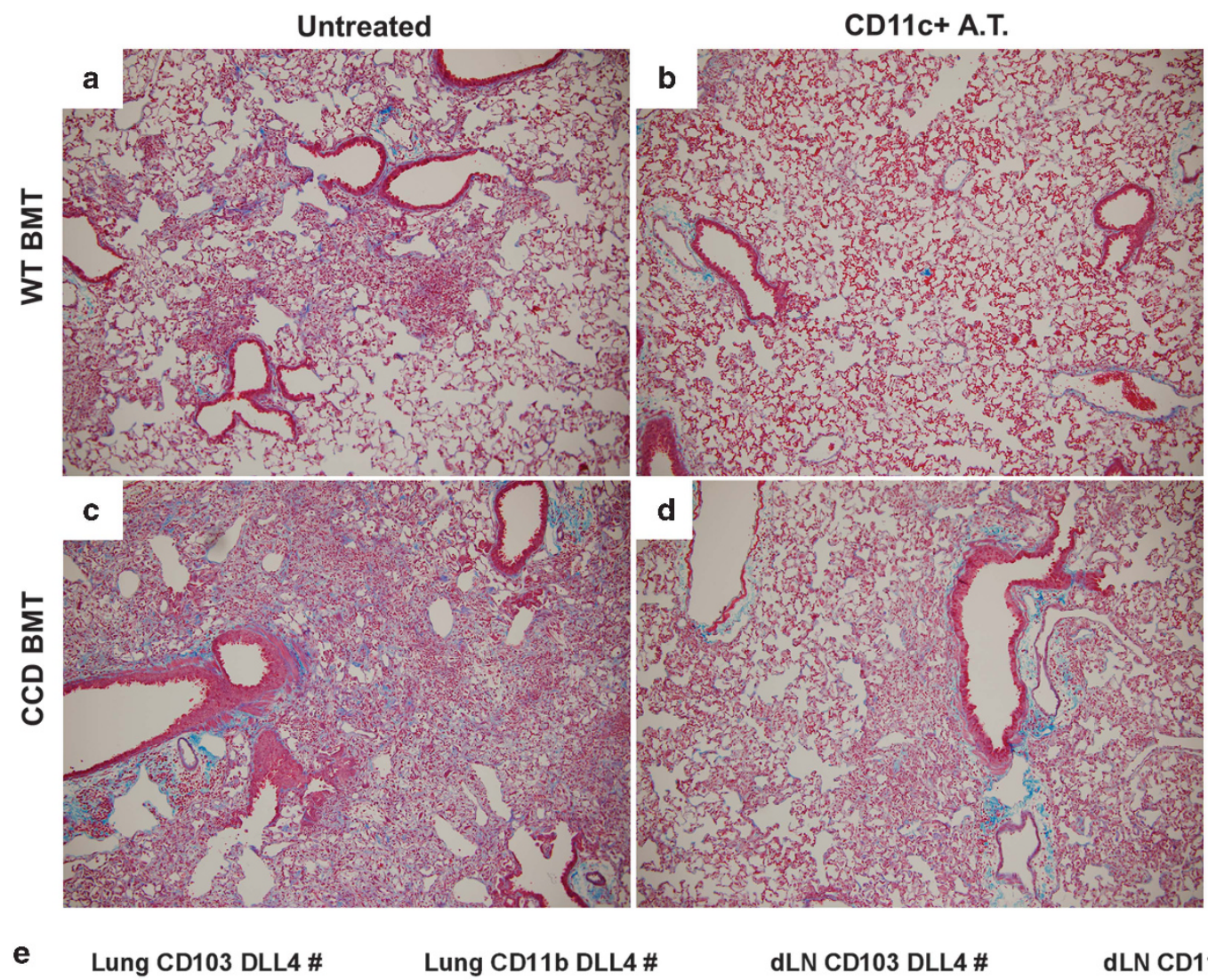

Lung CD11b DLL4 \#

dLN CD103 DLL4 \#

dLN CD11b DLL4 \#
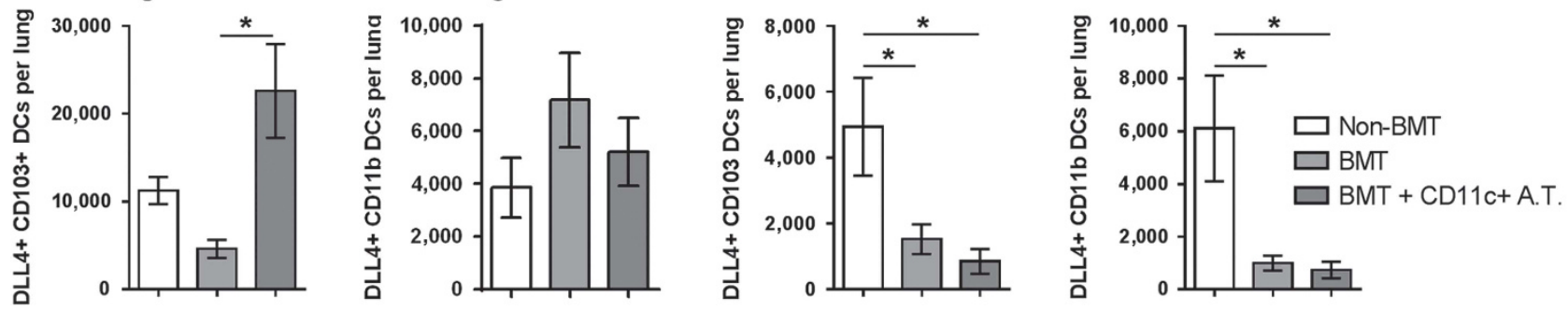

f
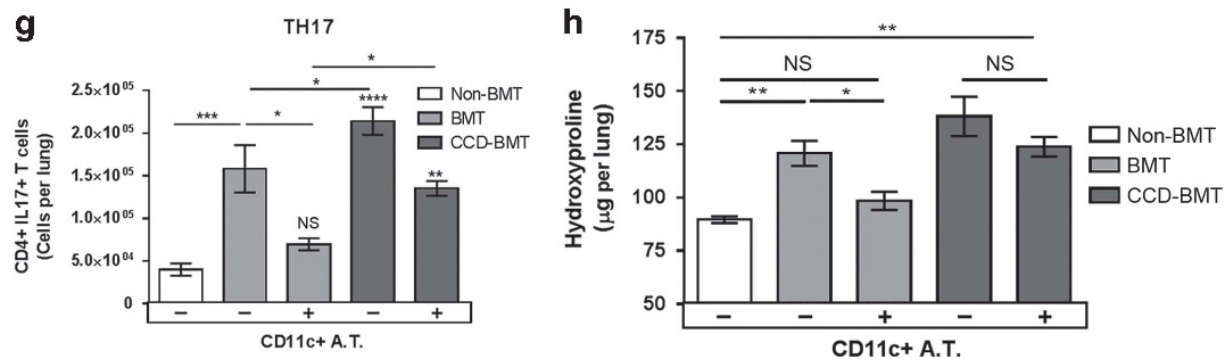

Figure 5 CD4-Cre-DNMAML-bone marrow transplant (CCD-BMT) mice are resistant to CD11c + adoptive transfer. Formalin-fixed paraffin-embedded (FFPE) sections were prepared from $\gamma$-herpesvirus-68 ( $\gamma \mathrm{HV}$-68)-infected animals at 21 days postinfection (dpi) and stained with Masson's trichrome to highlight collagen. (a and c) BMT or CCD-BMT mice, respectively, without adoptive transfer of wild-type (WT) CD11c + cells. (b and d) BMT or CCD-BMT mice with adoptive transfer of WT CD11c + cells. All images are shown at original magnification $\times 100$. (e) Flow cytometric analysis of DLL4 + , CD103 + , or CD11b + dendritic cells (DCs) from either lung or lung draining lymph node (dLN) at 7 dpi. (f) Indicated mouse groups were infected with $\gamma \mathrm{HV}-68$ for 7 days. CD4 + T cells were magnetically isolated from single-cell suspension of collagenase-digested lung tissue and analyzed by quantitative real-time PCR (qRT-PCR) for Hes 1 transcript ( $n=4-5$ mice per group). (g) Flow cytometric analysis of lung-infiltrating interleukin-17-positive $(\mathrm{IL}-17+$ ), CD4 + T cells (Th17 cells) taken from collagenase-digested lungs at $7 \mathrm{dpi}$. Cells were stimulated for $4 \mathrm{~h}$ with phorbol 12-myristate 13-acetate (PMA) and ionomycin before subsequent intracellular cytokine staining ( $n=12$ mice per group). (h) Mice were infected with $\gamma \mathrm{HV}$-68. Twenty-one days postinfection lungs were harvested and analyzed for collagen content by hydroxyproline assay ( $n=7-10$ mice per group). Statistical significance was calculated by analysis of variance (ANOVA). ${ }^{*} P<0.05,{ }^{\star \star} P<0.01,{ }^{* * *} P<0.001$, and ${ }^{* * *} P<0.0001$; NS $=$ not significant. Statistical comparisons that are labeled directly over the bars in panel $g$ are in comparison with non-BMT mice. 
hydroxyproline assay. In agreement with the histological analysis, WT BMT mice that had received adoptive transfer of CD11c + cells had significantly less collagen deposition than nontransferred BMT mice (Figure 5h). In contrast, CCD-BMT mice that received $\mathrm{CD} 11 \mathrm{c}+$ cell transfer did not show a decrease in collagen deposition in comparison with nontransferred CCD-BMT mice and collagen levels in these mice remained significantly elevated in comparison with nonBMT mice (Figure 5h).

In vitro culturing of lung leukocytes with recombinant DLL4 restores Notch signaling and decreases production of IL-17

We next attempted to restore Notch signaling by culturing purified lung leukocytes isolated from WT or BMT mice with plate-bound recombinant DLL4 (rDLL4). In agreement with in vivo observations, lung leukocytes cultured for $24 \mathrm{~h}$ in the absence of rDLL4 expressed lower levels of the Notch target gene Hes1 (Figure 6a). Addition of rDLL4 increased the expression of Hes 1 in BMT leukocytes, which correlated with a concomitant decrease in the expression of IL-17 transcript (Figure 6b). We next quantified the amount of IL-17 produced from either WT or BMT leukocytes cultured in the presence or absence of rDLL4 by ELISA. In agreement with the level of IL17 transcript measured by qRT-PCR, lung leukocytes from BMT mice cultured with rDLL4 secreted less IL-17 (Figure $\mathbf{6 b}, \mathbf{c}$ ). As a control, leukocytes isolated from the lungs of T-cell Notch signaling-deficient CCD-BMT mice were resistant to the effects of rDLL4 and produced increased amounts of IL-17 in comparison with rDLL4-treated WT-BMT lung leukocytes (Figure 6c).
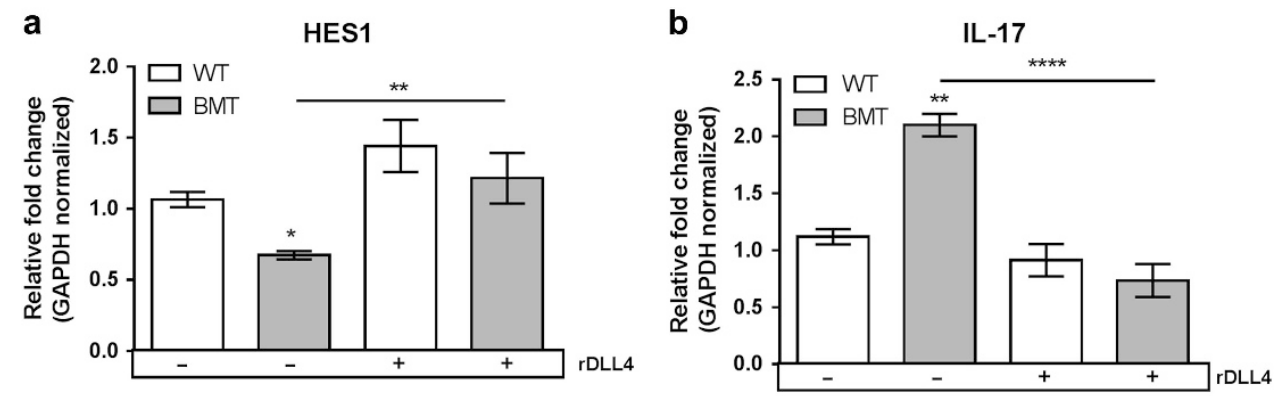

\section{DISCUSSION}

The impact of Notch signaling during the process of T-cell activation is complex and can range from activating to inhibitory depending on a variety of factors including: which specific Notch receptors and ligands are engaged, the type of T cells and APCs involved (naïve vs. previously activated or memory T cells) and the costimulatory and cytokine environment experienced by the $\mathrm{T}$ cell during activation. ${ }^{36,37}$ Here we present evidence that the loss of CD $4+$ T-cell Notch signaling during $\gamma \mathrm{HV}-68$ infection following BMT promotes the differentiation of Th17 cells and facilitates the development of IL-17-driven pneumonitis and pulmonary fibrosis that resembles features of human IPS and bronchiolitis obliterans syndrome post-transplant.

In contrast to some previously reported studies, which suggested that activation of the Notch signaling pathway in $\mathrm{T}$ cells preferentially enhanced IL-17 production, ${ }^{14,15}$ we found that $\mathrm{CD} 4+\mathrm{T}$ cells isolated from the lungs of BMT mice exhibited an increased capacity to produce IL-17; however, production of IL-17 correlated with a decrease in Hes1 and Notch1 expression, indicating a suppressive effect of Notch signaling on IL-17 production following BMT. These outcomes are likely due to loss of Notch1 as Notch2 expression does recover by 7 dpi. Furthermore, although not apparent in the normalized expression values shown in Figure 2, Notch2 was expressed at a much lower level than Notch1 under basal conditions. Several previous studies have shown that the expression of Hes 1 can suppress T-cell cytokine production and proliferation. Administration of activating $\alpha$-Notch 1 or $\alpha$ Notch2 antibodies increased the expression of Hes1 and

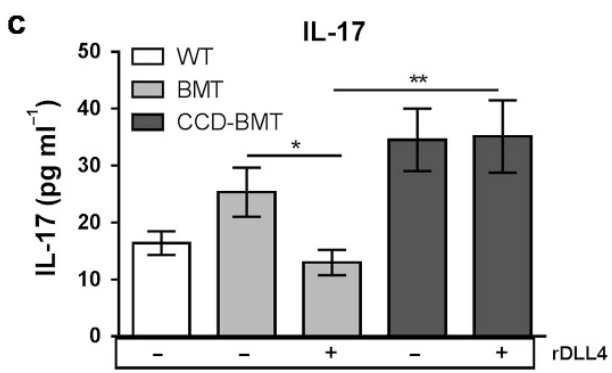

Figure 6 Ex vivo treatment of purified lung leukocytes with recombinant DLL4 restores Notch signaling and decreases interleukin-17 (IL-17) production. (a and b) Lung leukocytes were isolated from wild-type (WT) or bone marrow transplant (BMT) mice at 7 days postinfection (dpi) and cultured with or without $50 \mathrm{~nm}$ recombinant DLL4 for $24 \mathrm{~h}$. Total RNA was analyzed by quantitative real-time PCR (qRT-PCR) for the indicated transcript. (c) Lung leukocytes were isolated from either WT, BMT, or CD4-Cre-DNMAML-BMT (CCD-BMT) mice at $7 \mathrm{dpi}$, incubated for $24 \mathrm{~h}$ with or without $50 \mathrm{nM}$ DLL4. Supernatants were harvested and analyzed for IL-17 by enzyme-linked immunosorbent assay (ELISA). Statistical significance was calculated by analysis of variance (ANOVA). ${ }^{\star} P<0.05$, ${ }^{\star \star} P<0.01$, ${ }^{* \star *} P<0.001$, and ${ }^{* \star * \star} P<0.0001$ ( $n=4-5$ mice per group)., 
decreased phosphorylation of AKT leading to decreased secretion of IL-2. ${ }^{36,38}$ Likewise, genetic ablation of Notch1 and Notch2, specifically in T cells, led to increased expression of RoR $\gamma \mathrm{T}$ and Th17 differentiation. ${ }^{39}$ Furthermore, a specific jagged1-Notch1 interaction was identified in $\mathrm{T}$ cells that suppressed production of IL-17 produced because of TGF- $\beta$ and IL- 6 stimulation. ${ }^{20}$ Thus, it is plausible that the decreased expression of Notch1/Hes1 by CD $4+\mathrm{T}$ cells subsequently increased production of IL-17 following BMT.

Interestingly, DLL4 expression was downregulated on BMT $\mathrm{CD} 11 \mathrm{c}+\mathrm{APCs}$ in the absence of infection (Figure 1a). Likewise, Notch1 and Hes1 expression were decreased in naïve $\mathrm{T}$ cells isolated from the spleens of noninfected BMT mice (Figure 2, $0 \mathrm{dpi}$ ), indicating that the processes of radio conditioning or immune reconstitution following conditioning may facilitate the generation of a pro-IL-17/Th17 environment. However, non-BMT CCD mice infected with $\gamma \mathrm{HV}-68$ do not develop IPS-like pneumonitis or fibrosis even though they have significantly higher viral loads at $7 \mathrm{dpi}$ (Supplementary Figure S3A-C). While IFN $\gamma$ levels were reduced in non-BMT CCD mice following $\gamma \mathrm{HV}-68$ infection, IL-17 levels were not elevated (Supplementary Figure S3C,D). Furthermore, uninfected BMT mice do not develop fibrotic pathology by $21 \mathrm{dpi}^{26}$ Thus, it is likely that the conditioning regimen followed by an infectious stimulus is necessary to drive full elaboration of the Th17 response. In this regard, we have previously shown that lung epithelial cells are potent producers of TGF $\beta$ post-BMT, further, CD11c + cells isolated from $\gamma \mathrm{HV}-68$ infected BMT mice secrete pro-Th17 cytokines such as IL-6, IL-23, and TGF $\beta$, which could help promote robust Th17 responses. ${ }^{27,40}$

We observed decreased expression of the Notch ligand DLL4 on CD11c + APCs following syngeneic BMT, but this result is in contrast to literature related to allo-transplantation and graft-versus-host disease (GVHD). DLL4 expression has most recently been attributed to a population of hyper-inflammatory plasmacytoid-like DCs that are associated with acute GVHD following allogeneic BMT..$^{31,33,34}$ These DLL4-hi inflammatory plasmacytoid-like DCs express CD11b and B220 and drive robust proliferation of alloreactive $\mathrm{T}$ cells that produce high levels of IFN $\gamma$ and IL-17. ${ }^{34}$ Interestingly, blockade of DLL4 using $\alpha$-DLL4 therapy, or genetic ablation of T-cell Notch signaling, was shown to lessen IFN $\gamma$ and IL-17 production during acute GVHD improving disease outcomes. ${ }^{29,34}$ However, adoptive transfer of alloreactive $\mathrm{CD} 4+\mathrm{T}$ cells that had been cultured specifically with, Flt3-matured, DLL4-hi DCs were unable to mediate experimental GVHD even though they produced high levels of both IFN $\gamma$ and IL-17. ${ }^{31}$ Thus, the ultimate role of DLL4 governing GVHD remains unclear and is dependent on the model system.

Given the previous data supporting an activating role of T-cell Notch signaling on Th17 differentiation during alloBMT, we were surprised to find that infiltration of DLL4-low $\mathrm{CD} 11 \mathrm{c}+\mathrm{APCs}$ drives IL-17 responses and fibrosis during IPSlike pulmonary complications associated with viral infections following syngeneic BMT. One explanation for the apparent disparate functions of DLL4 in driving T-cell activation following BMT is that the subsets of DCs that are important for driving these immune reactions may be context-dependent, or may be completely different between models. The inflammatory plasmacytoid-like DCs observed during alloreactive GVHD are thought to be host-derived and spike in number very early ( 3 days) after transplant and reduce in number by 7 days post-BMT. ${ }^{34}$ Our model uses fully immune-reconstituted BMT mice (5 weeks post-BMT at the time of infection) and presumably these inflammatory plasmacytoid-like DCs would be low in number in our model.

Further, DCs are highly heterogeneous with many specialized subsets. For instance, the lung contains populations of DCs that are either CD11b + CD103 - or vice versa, while the major population in the intestinal lamina propria are $\mathrm{CD} 11 \mathrm{~b}+$ CD103 + DCs. ${ }^{41-43}$ Both lung and intestinal CD11b + DCs promote Th17 responses; however, CD103 + CD11b - DCs are thought to promote exclusively Th1 responses. ${ }^{41,44,45}$ Interestingly, we found that the expression of DLL4 was preferentially reduced on the CD103 $+\mathrm{CD} 11 \mathrm{~b}-\mathrm{DC}$ subset in the lungs of syngeneic BMT mice following $\gamma \mathrm{HV}-68$ infection. It is plausible that the lack of DLL4 on CD103 + DCs is partially responsible for the decreases inTh1 differentiation and IFN $\gamma$ production observed in BMT mice in response to $\gamma \mathrm{HV}-68$, and that in the absence of a proper Th1 response, a Th17 response is generated instead.

We previously published that adoptive transfer of CD11c + cells from non-BMT mice rescued fibrotic pathology. ${ }^{27} \mathrm{We}$ now show adoptive transfer of these DLL4-hi DCs preferentially increased the number of DLL4 + CD103 + DCs in the lungs following infection leading to a restoration of Hes1 expression in CD4 $+\mathrm{T}$ cells and decreased Th17 differentiation. We further demonstrated that T-cell Notch-deficient CCD-BMT mice were resistant to this effect and maintained Th17 differentiation and low CD4 + Hes1 expression following adoptive transfer of CD11c + cells, suggesting a specific interaction between Notch receptor expressing CD4 $+\mathrm{T}$ cells and DLL4 expressing CD103 + DCs in the lung (Figure 6). These data support a crucial role for DC-T cell Notch signaling in regulating IL-17 levels post-BMT; however, we do acknowledge that adoptive transfer of DCs into the CCD BMT mice has some impact on lowering Th17 cells and increasing the number of Th1 cells (Figure $\mathbf{5} \mathbf{f}$ and data not shown). This could reflect effects on radio-resistant host $\mathrm{T}$ cells, which would have been Notch sensitive or may suggest that there are additional Notch-independent effects of adoptively transferred DCs to limit Th17, and promote Th1, induction. Additionally, baseline secretion of low levels of IL-17 was observed in non-BMT-infected mice (Figure 6c). Several other lymphocyte cell types, e.g., $\gamma \delta$ T cells, ILC3s, and invariant NKT cells, are known to secrete IL-17 and could account for these Notch-independent secretion effects. However, given that the adoptive transfer of $\mathrm{CD} 11 \mathrm{c}+$ cells restored Notch signaling specifically in CD4 + Tcells and this correlated with decreased number of lung Th17 cells, we conclude that Notch signaling specifically acts to suppress IL-17 responses from CD4+ sources following BMT and viral infection. 
While human IPS is defined as being noninfectious, recent studies using more sensitive PCR techniques have demonstrated that over $50 \%$ of IPS cases are characterized by a previously undetected HV infection, HHV6. ${ }^{46-48}$ These clinical data suggest that IPS could be subsequent to an occult infectious insult. This is consistent with our data showing clearance of lytic virus by $10 \mathrm{dpi}$, but development of severe pneumonitis and fibrosis by $21 \mathrm{dpi}$ in the syngeneic BMT mice. Additionally, in a study analyzing 738 HSCT patients at the University of Michigan, both HHV6 and EBV infections within the first 100 days following transplant were strongly correlated with the development of IPS, with associated hazard ratios of 5.9 and 10, respectively (X Zhou, unpublished observation). Thus, while IPS can certainly manifest because of alloimmunity following HSCT, ${ }^{6}$ we strongly feel that infection with HVs is an additional stimulus to the development of pulmonary pathology following HSCT.

In summary, our results have demonstrated a selective loss of DLL4 that occurs on lung DCs at 5 weeks post-BMT, when immune reconstitution is complete. Furthermore, there is basal loss of Notch1 and Notch2 receptors on T cells post-BMT at this same time point. In the syngeneic BMT setting, this defect in Notch signaling promoted a robust Th17 response, which worsened pneumonitis and fibrosis. We have previously shown the ability of IL-17 to promote lung mesenchymal cell activation (both proliferation and extracellular matrix deposition). ${ }^{27}$ This pathologic Th17 response in the syngeneic setting is largely restored by adoptive transfer of primed DCs from nontransplanted mice, suggesting that in the setting of autologous HSCT complicated by HV infection, that cellular adoptive therapy or strategies to activate Notch signaling on $T$ cells may have merit. Given the realization that pulmonary sequela of HSCT are often complicated by occult HV infection, this may provide some insight into the etiology of these complications. Further work will be needed to identify strategies and time frames to promote anti-viral response while limiting GHVD in allogeneic transplants and fibrotic outcomes in both autologous and allogeneic transplant settings.

\section{METHODS}

Cell lines, virus strains, and mouse lines. Murine $\gamma \mathrm{HV}-68$ (strain WUMS VR-1465) was purchased from ATCC (Manassas, VA) and was propagated and titrated on NIH 3T12 fibroblast monolayers also purchased from ATCC. T-cell Notch-deficient mice (CCD mice) expressing a floxed dominant-negative copy of the Notch transcriptional activator MAML in combination with a Cre recombinase gene under the control of the $\mathrm{CD} 4$ promoter were first described in ref. $^{29}$ and were generously provided to us by Dr. Ivan Maillard (University of Michigan, Ann Arbor, MI). Mice were maintained by mating of homozygous (flox/flox) to each other and were genotyped for the presence of the floxed DNMAML and CD4 Cre genes before use. Control C57BL/6J mice were purchased from Jackson Laboratories (Bar Harbor, ME). All mice were used between 6 and 8 weeks of age and were housed in specific pathogen-free conditions. Experiments were approved by the University of Michigan Institutional Animal Committee on Use and Care. Syngeneic bone marrow transplantation has been previously described in ref. ${ }^{26}$ In short, C57BL/6J mice were lethally irradiated with $13 \mathrm{~Gy}$ (two split doses of $6.5 \mathrm{~Gy}$ spaced $3 \mathrm{~h}$ apart) from a ${ }^{137} \mathrm{Cs}$ radiation source. Mice were subsequently intravenously injected with $5 \times 10^{6}$ bone marrow cells isolated from either genetically identical C57BL/6J mice or congenic CCD mice. BMT mice were given acidified water $(\mathrm{pH} 3.3)$ for 3 weeks and then switched to plain water for an additional 2 weeks. After a 5-week reconstitution period, BMT or control mice were infected intranasally with $5 \times 10^{4} \mathrm{PFU} \gamma \mathrm{HV}-68$.

Preparation of single-cell suspensions from lung tissue and flow cytometry. Collagenase digestion of mouse lung tissue was previously described in ref. ${ }^{30}$ In short, mice were euthanized by $\mathrm{CO}_{2}$ asphyxiation after which perfusion was carried out by injecting 3-5 $\mathrm{ml}$ of phosphatebuffered saline through the right ventricle of the heart. Lungs were resected, minced with scissors, and digested in complete Dulbecco's modified Eagle's medium containing $15 \mathrm{mg} \mathrm{ml}^{-1}$ collagenase A (Roche, Indianapolis, IN), and 2,500 U of DNase I (Sigma-Aldrich, St Louis, MO) for $30 \mathrm{~min}$ at $37^{\circ} \mathrm{C}$. Digested tissue was disrupted through a $10 \mathrm{ml}$ syringe, filtered through a $100 \mu \mathrm{m}$ pore size nytex screen, and centrifuged through a $20 \%$ Percoll solution in serum-free media. A total of $10 \times 10^{6}$ cells were then stained with appropriately diluted fluorophore-conjugated antibodies for $30 \mathrm{~min}$. For intracellular cytokine staining cells were diluted to $1 \times 10^{6} / \mathrm{ml}$ and stimulated for $4 \mathrm{~h}$ with phorbol 12 -myristate 13 -acetate $\left(10 \mathrm{ng} \mathrm{ml}^{-1}\right)$, ionomycin $(10 \mu \mathrm{M})$, and Golgi-stop reagent (BD Bioscience, San Jose, CA). Antibodies used in this study are as follows: anti-CD45, CD11b, CD4, IL-17A, MHCII (I-A ${ }^{\mathrm{b}}$ ), CD103, SiglecF (BD Bioscience), CD11c, IFN $\gamma$ (eBioscience, San Diego, CA), DLL1, DLL4, Jagged1, Jagged2, and CD64 (BioLegend, San Diego, CA).

Preparation of RNA and quantitative real-time PCR. Total RNA was extracted from either whole lung tissue or purified cells with TRIzol reagent (ThermoFisher, Waltham, MA) following the manufacturer's directions. One hundred nanogram of RNA per sample was analyzed using Taqman RNA to CT Real-Time Master Mix (ThermoFisher) on an ABI StepOnePlus Thermocycler (ThermoFisher). Primers used in this study are detailed in Table 1.

Preparation of lung tissue sections for histology. Formalin-fixed paraffin-embedded lung sections were prepared as follows. Mice were euthanized by $\mathrm{CO}_{2}$ asphyxiation, after which $3-5 \mathrm{ml}$ of phosphatebuffered saline was perfused through the right ventricle of the heart. Lungs were infused with $1 \mathrm{ml} 10 \%$ formalin solution through the trachea and fixed for $24 \mathrm{~h}$, after which lungs were dehydrated in $70 \%$ ethanol, embedded in paraffin and sectioned to a $10 \mu \mathrm{M}$ thickness. Lung sections were subsequently stained with hematoxylin and eosin or Masson's Trichrome stain to highlight collagen fibers.

Quantitation of collagen by hydroxyproline assay. Collagen content was assessed in whole lung homogenates using the hydroxyproline assay as described in ref. ${ }^{30}$

Cytokine quantitation. Percoll-purified lung leukocytes from collagenase-digested lung tissue or magnetically isolated CD4 $+\mathrm{T}$ cells $\left(3 \times 10^{6}\right.$ per sample) were cultured for $24 \mathrm{~h}$ with or without additional skewing cytokines. Clarified supernatants were subsequently analyzed for the indicated cytokines using DuoSet ELISA Assays (R\&D Systems, Minneapolis, MN). Recombinant murine DLL4 (R\&D Systems) was plate bound to tissue culture dishes at a concentration of $50 \mathrm{~nm}$ in phosphate-buffered saline for $3 \mathrm{~h}$ at $37^{\circ} \mathrm{C}$. Plates were washed $3 \times$ with sterile phosphate-buffered saline before addition of purified leukocytes in complete media.

Statistical analysis. Statistical analysis was carried out using GraphPad Prism v6.01 (GraphPad Software, La Jolla, CA). Figures that compare only two means were analyzed by Student's T-test. Analysis of variance (ANOVA) in conjunction with Tukey's multiple comparisons post-test was used in experiments where three or more means were analyzed together. All experiments were conducted in, at least, duplicate. $N$ values and other pertinent statistical information for representative experiments are given in individual figure legends. 


\section{Table 1 Primers and probes used for qRT-PCR}

\begin{tabular}{lll}
\hline Gene name & \multicolumn{2}{c}{ Primer sequence } \\
\hline IL-17A & Forward & 5'-CCGCAATGAAGACCCTGATAG-3' \\
& Reverse & 5'-GCTTCCCTCCGCATTGA-3' \\
& Probe & 5'-GGGAAGCTCAGTGCCGCCAG-3'
\end{tabular}

$\begin{array}{lcl}\text { Hes1 } & \begin{array}{c}\text { Forward } \\ \text { Reverse } \\ \text { Probe }\end{array} & \text { 5'-GGCCTCTGAGCACAGAAAGT-3' } \\ & \text { 5'-TCCGGGAGCTATCTTCTTA-3' } \\ \text { Hes5 } & \text { Forward } & \text { 5'GCAGCATAGAGCAGCTGAAG-3' } \\ & \text { Reverse } & \text { 5'-GAAGGCTTGCTGTGTTCA-3' } \\ & \text { Probe } & \text { 5'-CGCGAACTCCTGCTCCAGCA-3' } \\ & & \\ \text { Hey1 } & \text { Forward } & \text { 5'-TGCAGGAGGGAAAGGTATT-3' } \\ & \text { Reverse } & \text { 5'-GAGGCATCGAGTCCTTCAAT-3' } \\ & \text { Probe } & \text { 5'-AATGCCTGGCCGAAGTTGCC-3' }\end{array}$

\begin{tabular}{|c|c|c|}
\hline Notch1 & Forward & 5'-CCAGGAAACAACTGCAAGAA-3' \\
\hline & Reverse & 5'-AGTACTGACCCGTCCACTCC-3' \\
\hline & Probe & 5'-CCTACAАTTGCCGCTGCCCA-3' \\
\hline
\end{tabular}

\begin{tabular}{|c|c|c|}
\hline Notch2 & Forward & 5'-TGAGAGCTTCAGCTGCTTGT-3' \\
\hline & Reverse & 5'-AGTGTTGTGGCAGACACCAT-3' \\
\hline & Probe & 5'-TTACCTTGCCAGCCAGGAGCA-3 \\
\hline
\end{tabular}

$\begin{array}{cl}\text { DLL1 } 1 \text { 5orward } & \text { 5'CTGGCCAGGTACCTTCTCTC-3' } \\ \text { Reverse } & \text { 5'-CCATTCTTCTCCCACAGTGA-3' } \\ \text { Probe } & \text { 5'-CCGCCTGACCACACAGAGGC-3' }\end{array}$

\begin{tabular}{|c|c|c|}
\hline \multirow[t]{3}{*}{ DLL4 } & Forward & 5'-CGTCGTCAGGGACAAGAATA-3' \\
\hline & Reverse & 5'-GAGTTTCCTGGCGAAGTCTC-3' \\
\hline & Probe & 5'-CCTGGCCGGGAACCTTCTCA-3' \\
\hline
\end{tabular}

\begin{tabular}{|c|c|c|}
\hline Jagged1 & Forward & 5'-GACTCATCAGCCCTGTCTCA-3' \\
\hline & Reverse & 5'-AGCATGCTCAGCAATTTCAC-3' \\
\hline & Probe & 5'-CCCGAGTAGCCCTCTGGGCA-3' \\
\hline
\end{tabular}

\begin{tabular}{|c|c|c|}
\hline Jagged2 & Forward & 5'-CAATCCCTGTGTGAATGGAG-3' \\
\hline & Reverse & 5'-TGGTGTTATGTGTGCAGGTG-3' \\
\hline & & \\
\hline
\end{tabular}

qRT-PCR, quantitative real-time PCR.

SUPPLEMENTARY MATERIAL is linked to the online version of the paper at http://www.nature.com/mi

\section{ACKNOWLEDGMENTS}

We thank Dr. Maillard for provision of the CCD mice, helpful discussions, and critical reading of the manuscript. This work was supported by $\mathrm{NIH}$ grants HL127805, HL115618, and Al117229 (to B.B.M.). S.J.G. and X.Z. were also supported by NIH T32 HL007749 and 2UL1TR000433.

\section{AUTHOR CONTRIBUTIONS}

S.J.G. designed and performed experiments, analyzed and interpreted data, and wrote the manuscript. X.F.Z. designed and performed experiments and edited the manuscript. M.N.F. performed experiments. C.W. performed experiments. B.B.M. designed experiments, analyzed and interpreted data, and edited the manuscript.

\section{DISCLOSURE}

The authors declared no conflict of interest.

c) 2018 Society for Mucosal Immunology

\section{REFERENCES}

1. Bouchlaka, M. N., Redelman, D. \& Murphy, W. J. Immunotherapy following hematopoietic stem cell transplantation: potential for synergistic effects. Immunotherapy 2, 399-418 (2010).

2. Hugle, T. \& Daikeler, T. Stem cell transplantation for autoimmune diseases. Haematologica 95, 185-188 (2010).

3. Afessa, B. \& Peters, S. G. Major complications following hematopoietic stem cell transplantation. Semin. Respir. Crit. Care Med. 27, 297-309 (2006).

4. Yoshihara, S., Yanik, G., Cooke, K. R. \& Mineishi, S. Bronchiolitis obliterans syndrome (BOS), bronchiolitis obliterans organizing pneumonia (BOOP), and other late-onset noninfectious pulmonary complications following allogeneic hematopoietic stem cell transplantation. Biol. Blood Marrow Transplant. 13, 749-759 (2007).

5. Varelias, A. et al. Lung parenchyma-derived IL-6 promotes IL-17Adependent acute lung injury after allogeneic stem cell transplantation. Blood 125, 2435-2444 (2015).

6. Mauermann, N. et al. Interferon-gamma regulates idiopathic pneumonia syndrome, a Th17 + CD4 + T-cell-mediated graft-versus-host disease. Am. J. Respir. Crit. Care Med. 178, 379-388 (2008).

7. Vittal, R. et al. IL-17 induces type $V$ collagen overexpression and EMT via TGF-beta-dependent pathways in obliterative bronchiolitis. Am. J. Physiol. Lung Cell. Mol. Physiol. 304, L401-L414 (2013).

8. Radtke, F., Fasnacht, N. \& Macdonald, H. R. Notch signaling in the immune system. Immunity 32, 14-27 (2010).

9. Maillard, I., Fang, T. \& Pear, W. S. Regulation of lymphoid development, differentiation, and function by the Notch pathway. Annu. Rev. Immunol. 23, 945-974 (2005).

10. LaVoie, M. J. \& Selkoe, D. J. The Notch ligands, Jagged and Delta, are sequentially processed by alpha-secretase and presenilin/gamma-secretase and release signaling fragments. J. Biol. Chem. 278, 34427-34437 (2003).

11. Han, J., Allalunis-Turner, J. \& Hendzel, M. J. Characterization and comparison of protein complexes initiated by the intracellular domain of individual Notch paralogs. Biochem. Biophys. Res. Commun. 407, 479485 (2011).

12. Amsen, D., Antov, A. \& Flavell, R. A. The different faces of Notch in T-helpercell differentiation. Nat. Rev. Immunol. 9, 116-124 (2009).

13. Amsen, D., Blander, J. M., Lee, G. R., Tanigaki, K., Honjo, T. \& Flavell, R. A. Instruction of distinct CD4 T helper cell fates by different notch ligands on antigen-presenting cells. Cell 117, 515-526 (2004).

14. Mukherjee, S., Schaller, M. A., Neupane, R., Kunkel, S. L. \& Lukacs, N. W. Regulation of T cell activation by Notch ligand, DLL4, promotes IL-17 production and Rorc activation. J. Immunol. 182, 7381-7388 (2009).

15. Keerthivasan, S. et al. Notch signaling regulates mouse and human Th17 differentiation. J. Immunol. 187, 692-701 (2011).

16. Hoyne, G. F. et al. Serrate1-induced notch signalling regulates the decision between immunity and tolerance made by peripheral CD4(+) T cells. Int. Immunol. 12, 177-185 (2000).

17. Qu, S. Y. et al. Der p2 recombinant bacille Calmette-Guerin priming of bone marrow-derived dendritic cells suppresses Der p2-induced T helper17 function in a mouse model of asthma. Respirology 19, 122-131 (2014). 
18. Schaller, M. A. et al. Notch ligand Delta-like 4 regulates disease pathogenesis during respiratory viral infections by modulating Th2 cytokines. J. Exp. Med. 204, 2925-2934 (2007).

19. Ting, H. A., Schaller, M. A., de Almeida Nagata, D. E., Rasky, A. J., Maillard, I. P. \& Lukacs, N. W. Notch ligand delta-like 4 promotes regulatory T cell identity in pulmonary viral infection. J Immunol 198, 1492-1502 (2017).

20. Wang, Y. et al. Jagged-1 signaling suppresses the IL-6 and TGF-beta treatment-induced Th17 cell differentiation via the reduction of RORgammat/LL-17A/L-17F/IL-23a/LL-12rb1. Sci. Rep. 5, 8234 (2015).

21. You, P. et al. Jagged-1-HES-1 signaling inhibits the differentiation of TH17 cells via ROR gammat. J. Biol. Regul. Homeost. Agents 27, 79-93 (2013).

22. Rauen, T. et al. cAMP-responsive element modulator alpha (CREMalpha) contributes to decreased Notch-1 expression in T cells from patients with active systemic lupus erythematosus (SLE). J. Biol. Chem. 287, 4252542532 (2012).

23. Sarawar, S. R., Cardin, R. D., Brooks, J. W., Mehrpooya, M., Tripp, R. A. \& Doherty, P. C. Cytokine production in the immune response to murine gammaherpesvirus 68. J. Virol. 70, 3264-3268 (1996).

24. Sarawar, S. R., Lee, B. J. \& Giannoni, F. Cytokines and costimulatory molecules in the immune response to murine gammaherpesvirus-68. Viral Immunol. 17, 3-11 (2004).

25. Sparks-Thissen, R. L., Braaten, D. C., Hildner, K., Murphy, T. L., Murphy, K. M. \& Virgin, H. W. t. CD4 T cell control of acute and latent murine gammaherpesvirus infection requires IFNgamma. Virology 338, 201-208 (2005).

26. Coomes, S. M., Farmen, S., Wilke, C. A., Laouar, Y. \& Moore, B. B. Severe gammaherpesvirus-induced pneumonitis and fibrosis in syngeneic bone marrow transplant mice is related to effects of transforming growth factorbeta. Am. J. Pathol. 179, 2382-2396 (2011).

27. Zhou, X. et al. Bone marrow transplantation alters lung antigen-presenting cells to promote $\mathrm{TH} 17$ response and the development of pneumonitis and fibrosis following gammaherpesvirus infection. Mucosal Immunol. 9, 610620 (2016).

28. Gurczynski, S. J., Procario, M. C., O'Dwyer, D. N., Wilke, C. A. \& Moore, B. B. Loss of CCR2 signaling alters leukocyte recruitment and exacerbates gamma-herpesvirus induced pneumonitis and fibrosis following bone marrow transplantation. Am. J. Physiol. Lung Cell. Mol. Physiol. 311, L611-L627 (2016).

29. Sandy, A. R. et al. T cell-specific notch inhibition blocks graft-versus-host disease by inducing a hyporesponsive program in alloreactive CD4 + and CD8 + T cells. J. Immunol. 190, 5818-5828 (2013).

30. Moore, B. B. et al. Protection from pulmonary fibrosis in the absence of CCR2 signaling. J. Immunol. 167, 4368-4377 (2001).

31. Mochizuki, K. et al. Programming of donor Tcells using allogeneic delta-like ligand 4-positive dendritic cells to reduce GVHD in mice. Blood 127, 32703280 (2016).

32. Schaller, M. A., Allen, R. M., Kimura, S., Day, C. L. \& Kunkel, S. L. Systemic expression of Notch ligand delta-like 4 during mycobacterial infection alters the T cell immune response. Front. Immunol. 7, 527 (2016).
33. Meng, L. et al. The Notch ligand DLL4 defines a capability of human dendritic cells in regulating Th1 and Th17 differentiation. J. Immunol. 196, 1070-1080 (2016).

34. Mochizuki, K. et al. Delta-like ligand 4 identifies a previously uncharacterized population of inflammatory dendritic cells that plays important roles in eliciting allogeneic T cell responses in mice. J. Immunol. 190, 3772-3782 (2013).

35. Huang, H. M. et al. Notch ligand delta-like 4-pretreated dendritic cells alleviate allergic airway responses by enhancing IL-10 production. PLOS ONE 8, e63613 (2013).

36. Eagar, T. N., Tang, Q., Wolfe, M., He, Y., Pear, W. S. \& Bluestone, J. A. Notch 1 signaling regulates peripheral Tcell activation. Immunity 20, 407-415 (2004).

37. Laky, K., Evans, S., Perez-Diez, A. \& Fowlkes, B. J. Notch signaling regulates antigen sensitivity of naive $\mathrm{CD} 4+\mathrm{T}$ cells by tuning costimulation. Immunity 42, 80-94 (2015).

38. Tian, C., Yu, Y., Jia, Y., Zhu, L. \& Zhang, Y. HES1 activation suppresses proliferation of leukemia cells in acute myeloid leukemia. Ann. Hematol. 94, 1477-1483 (2015).

39. Coutaz, M. et al. Notch regulates Th17 differentiation and controls trafficking of IL-17 and metabolic regulators within Th17 cells in a contextdependent manner. Sci. Rep. 6, 39117 (2016).

40. Domingo-Gonzalez, R. et al. Transforming growth factor-beta induces microRNA-29b to promote murine alveolar macrophage dysfunction after bone marrow transplantation. Am. J. Physiol. Lung Cell. Mol. Physiol. 308, L86-L95 (2015).

41. Schlitzer, A. et al. IRF4 transcription factor-dependent CD11b + dendritic cells in human and mouse control mucosal IL-17 cytokine responses. Immunity 38, 970-983 (2013).

42. Satpathy, A. T. et al. Notch2-dependent classical dendritic cells orchestrate intestinal immunity to attaching-and-effacing bacterial pathogens. Nat. Immunol. 14, 937-948 (2013).

43. Desch, A. N. etal. CD103 + pulmonary dendritic cells preferentially acquire and present apoptotic cell-associated antigen. J. Exp. Med. 208, 17891797 (2011).

44. Liang, J. et al. Inflammatory Th1 and Th17 in the intestine are each driven by functionally specialized dendritic cells with distinct requirements for MyD88. Cell Rep. 17, 1330-1343 (2016).

45. Martinez-Lopez, M., Iborra, S., Conde-Garrosa, R. \& Sancho, D. Batf3dependent $C D 103+$ dendritic cells are major producers of IL-12 that drive local Th1 immunity against Leishmania major infection in mice. Eur. J. Immunol. 45, 119-129 (2015).

46. Neurohr, C. et al. Human herpesvirus 6 in bronchalveolar lavage fluid after lung transplantation: a risk factor for bronchiolitis obliterans syndrome? Am. J. Transplant. 5, 2982-2991 (2005).

47. Versluys, A. B., Rossen, J. W., van Ewijk, B., Schuurman, R., Bierings, M. B. \& Boelens, J. J. Strong association between respiratory viral infection early after hematopoietic stem cell transplantation and the development of life-threatening acute and chronic alloimmune lung syndromes. Biol. Blood Marrow Transplant. 16, 782-791 (2010).

48. Seo, S. et al. Idiopathic pneumonia syndrome after hematopoietic cell transplantation: evidence of occult infectious etiologies. Blood 125, 37893797 (2015). 